\title{
Kinetička analiza izotermne razgradnje poli(etilen-oksidal modificiranog fenil hepta izobutil poliedarskim oligomernim silseskvioksanima
}

\author{
N. Stipanelov Vrandečić, M. Erceg, B. Andričić i P. Ćerdić \\ Kemijsko-tehnološki fakultet, Sveučilište u Splitu, R. Boškovića 35, 21000 Split, Hrvatska
}

\begin{abstract}
Sažetak
Čvrsti polimerni elektroliti na bazi poli(etilen-oksida) (PEO) i litijevih soli imaju slabu ionsku provodnost pri temperaturi uporabe, a osnovni razlog je visok stupanj kristalnosti PEO-a. Udio kristalne faze u PEO-u može se smanjiti dodatkom nanočestica, u koje spadaju i poliedarski oligomerni silseskvioksani (POSS). U ovom radu upotrijebljeni su metil-, fluoro- i kloro-fenil hepta izobutil poliedarski oligomerni silseskvioksani. Istraživan je njihov utjecaj na kinetiku izotermne razgradnje PEO-a. Aktivacijska energija, predeksponencijalni faktor i kinetički model izračunati su pomoću programa Netzsch Thermokinetics Professional. Utvrđeno je da se proces izotermne toplinske razgradnje odvija kroz jedan stupanj koji je najbolje opisan autokatalitičkim modelima.
\end{abstract}

\section{Ključne riječi}

Izotermna razgradnja, kinetička analiza, poliedarski oligomerni silseskvioksani, poli(etilen oksid)

\section{Uvod}

Poli(etilen-oksid) (PEO) je polimer koji se krajem dvadesetog stoljeća počeo upotrebljavati za izradu čvrstih polimernih elektrolita (engl. solid polymer electrolytes, SPE) u polimer-ionskim baterijama. Polimerni elektroliti su čvrsti ionski vodiči sastavljeni od polimera i u njemu "otopljene" anorganske soli, najčešće litijeve. Prednosti litij-ionskih polimernih baterija u odnosu na konvencionalne litij-ionske baterije su poboljšana mogućnost oblikovanja te poboljšana sigurnost i stabilnost. Međutim, litij-ionske polimerne baterije imaju slabu ionsku provodnost pri sobnoj temperaturi. lonska provodnost SPE-a na temelju PEO-a pri sobnoj temperaturi nije zadovoljavajuća zbog visoke kristalnosti PEO-a. ${ }^{1-7}$ Budući da se ionska provodnost odvija u amorfnoj fazi, ključno je smanjenje njegove kristalnosti, uz istodobno zadržavanje ili poboljšavanje ostalih svojstava, ponajprije mehaničkih i toplinskih. Jedan od načina na koji se može smanjiti udio kristalne faze u PEO-u je dodatak različitih nanopunila koja, efikasno dispergirana, mogu onemogućiti njegovu kristalizaciju. 8,9 Nanopunila, dodana $u$ relativno malim količinama, $u$ pravilu poboljšavaju fizikalna, kemijska i mehanička svojstva polimera. Međutim, nanopunila, poput slojevitih montmorilonita, mogu i smanjiti toplinsku postojanost PEO-a. ${ }^{10-11}$ Druga skupina nanočestica za koje se smatra da mogu poslužiti za pripravu polimernih nanomaterijala za SPE željenih svojstava su hibridne anorgansko-organske tvari. Poliedarski oligomerni silseskvioksani (POSS) naziv je za skupinu nanočestica s općom formulom $\left(\mathrm{RSiO}_{1.5}\right)_{\mathrm{n}}$, gdje R predstavlja atom

*Autor za dopisivanje: prof. dr. sc. Nataša Stipanelov Vrandečić e-pošta: nstip@ktf-split.hr

Rad je prezentiran na VII. hrvatskom simpoziju o kemiji i tehnologiji makromolekula 2019. vodika ili organsku funkcionalnu skupinu kao što su alkili, alkenili, akrilati, hidroksidi ili epoksidi. Struktura POSS-a može se opisati kao anorganska rešetka, sastavljena od atoma silicija i kisika u omjeru 2 : 3, na čije su vrhove kovalentnim vezama vezane organske funkcionalne skupine. ${ }^{12}$ Za razliku od drugih punila, prednost različitih POSS-a je činjenica da su to molekule. To istraživačima omogućava kombiniranje njihove strukture kaveza nano-veličine, koji su približnih dimenzija kao i polimerni segmenti te modificiranje sastava ovisno o polimernom sustavu u koji se žele dispergirati. ${ }^{13}$ Prednosti POSS-a su također njihova nehlapljivost, bez mirisa su i ekološki prihvatljivi.

U ovom radu uzorci poli(etilen-oksida) (PEO) modificiranog nanočesticama POSS-a pripremljeni su metodom taljenja. Istraživan je utjecaj POSS-a na kinetiku izotermne razgradnje poli(etilen-oksida).

\section{Eksperimentalni dio}

\subsection{Materijal}

Za pripremu polimernih nanokompozita upotrijebljeni su prahovi poli(etilen-oksida) molekulske mase $M_{\mathrm{w}}=300000 \mathrm{~g} \mathrm{~mol}^{-1}$ (proizvođača Dow Chemical) i fenil hepta izobutil poliedarskih oligomernih silseskvioksana (f,hib-POSS) sintetiziranih u Zavodu za građevinarstvo i arhitekturu Sveučilišta u Kataniji (Italija). ${ }^{13}$

Fenil hepta izobutil poliedarski oligomerni silseskvioksani (f,hib-POSSs) prikazuju se općom formulom $\mathrm{R}_{7} \mathrm{R}^{\prime}\left(\mathrm{SiO}_{1.5}\right)_{8}$, u kojoj je $\mathrm{R}$ izobutilna grupa, a $\mathrm{R}^{\prime}$ je monosupstituirana fenilna grupa. Supstituenti na fenilnoj grupi su metilna $i$ 

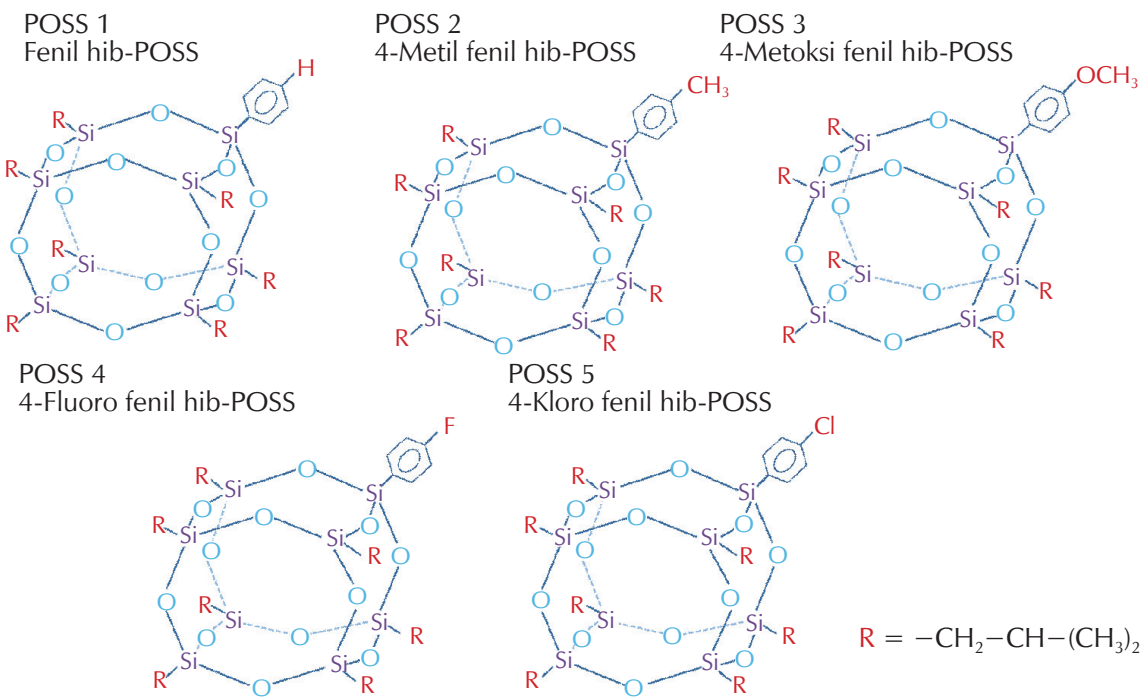

$\mathrm{R}=-\mathrm{CH}_{2}-\mathrm{CH}-\left(\mathrm{CH}_{3}\right)_{2}$

Slika 1 - Molekulska struktura fenil hepta izobutil poliedarskih oligomernih silseskvioksana upotrijebljenih za pripravu nanokompozita

Fig. 1 - Molecular structure of phenyl hepta isobutyl polyhedral oligomeric silsesquioxanes used for nanocomposite preparation

metoksi grupa te fluor i klor. Molekulska struktura, nazivi i kratice fenil hib-POSS-a prikazane su na slici 1.

\subsection{Priprema uzoraka}

Uzorci nanokompozita pripremljeni su metodom taljenja. 200 mg PEO praha i 10 mg f,hib-POSS praha homogenizirano je $u$ ahatnom tarioniku. Nakon toga isprešani su u pastile pomoću hidrauličke preše uz pritisak $50 \mathrm{~N} \mathrm{~mm}^{-2}$ te taljeni $8 \mathrm{~h}$ pri temperaturi $90{ }^{\circ} \mathrm{C}$.

\subsection{Izotermna termogravimetrijska razgradnja}

Uzorci mase $10 \pm 0,07 \mathrm{mg}$ razgrađivani su u termovagi (Perkin-Elmer Pyris 1 TGA) u struji dušika $\left(30 \mathrm{~cm}^{3} \mathrm{~min}^{-1}\right)$ pri temperaturama 360,370 i $380{ }^{\circ} \mathrm{C}$ u trajanju $60 \mathrm{~min}$. Uzorci su zagrijavani od početne temperature $50{ }^{\circ} \mathrm{C}$ do temperature izotermne razgradnje brzinom $200{ }^{\circ} \mathrm{C} \mathrm{min}^{-1}$. Prije početka mjerenja, sustav je stabiliziran pri početnoj temperaturi od $50{ }^{\circ} \mathrm{C} \mathrm{uz}$ protok dušika od $30 \mathrm{~cm}^{3} \mathrm{~min}^{-1} \mathrm{u}$ trajanju od $1 \mathrm{~h}$.

\subsection{Kinetička analiza}

Toplinska razgradnja polimera i polimernih mješavina spada $u$ heterogene procese. Tijekom toplinske razgradnje odvija se niz kemijskih reakcija i fizikalnih procesa s nekom ukupnom brzinom koja ovisi o brzini pojedinačnih procesa. Podatci potrebni za provođenje kinetičke analize procesa toplinske razgradnje mogu se dobiti primjenom termogravimetrije.

Kinetička analiza toplinske razgradnje u čvrstom stanju temelji se na kinetičkoj jednadžbi za reakcije u jednom stupnju:

$$
r=\frac{\mathrm{d} \alpha}{\mathrm{d} t}=k(T) \cdot f(\alpha),
$$

gdje je $r$ - brzina kemijske reakcije, $\alpha$ - konverzija, $t$ vrijeme, $k(T)$ - konstanta brzine reakcije, $f(\alpha)$ - kinetički model i $T$ - temperatura. Konstanta brzine reakcije može se odrediti iz Arrheniusove jednadžbe:

$$
k(T)=A \cdot \exp \left(-\frac{E}{R T}\right),
$$

gdje je $A$ - predeksponencijalni faktor, $E$ - aktivacijska energija, $R$ - opća plinska konstanta.

Uvrštavanjem jedn. (2) u jedn. (1) dobije se opća kinetička jednadžba:

$$
\frac{\mathrm{d} \alpha}{\mathrm{d} t}=A \cdot \exp \left(-\frac{E}{R T}\right) \cdot f(\alpha) .
$$

Vrijednosti $E, A$, i $f(\alpha)$ predstavljaju tzv. kinetički triplet i opisuju ukupan tijek procesa toplinske razgradnje bez obzira na njegovu složenost. Termogravimetrijom dobiveni podatci za kinetičku analizu odnose se na ukupnu brzinu procesa, a ne na brzine elementarnih stupnjeva, stoga i Arrheniusovi parametri (kinetički triplet) nisu stvarni, već ukupni (prividni) parametri procesa.

Određivanje kinetičkih parametara iz TG podataka najčešće se zasniva na uvrštavanju eksperimentalnih podataka u teorijske kinetičke modele (engl. model-fitting). Metoda je primjenjiva za izotermne i neizotermne uvjete i daje jedan par Arrheniusovih parametara, tj. jedan par vrijednosti aktivacijske energije i predeksponencijalnog faktora. Nekoliko različitih kinetičkih modela može opisivati jednu te istu TG krivulju, pa stoga pouzdana analiza podataka dobivenih termogravimetrijom zahtijeva niz TG krivulja sni- 
mljenih pri različitim temperaturama ili različitim brzinama zagrijavanja. Za izračunavanje aktivacijske energije, $E$, procesa toplinske razgradnje primjenjuju se diferencijalna ili integralna bezmodelna (engl. model-free) izokonverzijska metoda, koja omogućava izračunavanje prividne aktivacijske energije bez poznavanja oblika funkcije $f(\alpha)$.

Diferencijalna bezmodelna izokonverzijska metoda primjenjuje opću kinetičku jednadžbu zapisanu u logaritamskom obliku:

$$
\mathrm{n} \frac{\mathrm{d} \alpha}{\mathrm{d} t}=\ln A+\ln f(\alpha)-\frac{E}{R T} .
$$

Crtanjem $\ln (\mathrm{d} \alpha / \mathrm{d} t)$ u ovisnosti o $1 / T$ za $\alpha=$ konst, iz nagiba pravca moguće je izračunati aktivacijsku energiju.

Integralna bezmodelna izokonverzijska metoda primjenjuje integralni oblik opće kinetičke jednadžbe:

$$
\int_{0}^{\alpha} \frac{\mathrm{d} \alpha}{f(\alpha)}=g(\alpha)=A \cdot \exp \left(-\frac{E}{R T}\right) \cdot t
$$

Iz prethodne jednadžbe slijedi:

$$
\ln t=-\ln \frac{A}{g(\alpha)}+\frac{E}{R T}
$$

Prema preporukama International Confederation for Thermal Analysis and Calorimetry (ICTAC) kinetička analiza mora započeti određivanjem ovisnosti aktivacijske ener- gije o konverziji. Oblik te ovisnosti definira daljnji tijek kinetičke analize, odnosno metode izračunavanja ostalih kinetičkih parametara, predeksponencijalnog faktora $A$ i kinetičkog modela $f(\alpha) \cdot{ }^{14,15}$

U ovom radu kinetička analiza provedena je pomoću programa Netzsch Thermokinetics Professional. ${ }^{16}$ Program može obrađivati eksperimentalne podatke dobivene metodama toplinske analize, ponajprije termogravimetrijom (TGA), diferencijalnom pretražnom kalorimetrijom (DSC) ili diferencijalnom toplinskom analizom (DTA). U program je uključena izokonverzijska analiza za određivanje aktivacijske energije procesa i njezine ovisnosti o konverziji, zatim linearna regresijska analiza za jednostupanjske procese i viševarijantna nelinearna regresijska analiza za složene, višestupanjske procese te napredna statistička analiza. I linearna i viševarijantna nelinearna regresijska analiza temelje se na metodama prilagodbe velikog broja reakcijskih modela ${ }^{16}$ na eksperimentalne termogravimetrijske podatke. Najboljim modelom smatra se onaj koji daje najmanju razliku između izmjerenih i izračunatih vrijednosti, što se procjenjuje statističkim metodama, metodom najmanjih kvadrata i F-testom. Budući da se radi o statističkim metodama, treba imati na umu da statistički najbolji model ne mora nužno najbolje opisivati mehanizam procesa te je uvijek korisno vrijednosti tako dobivenih aktivacijskih energija usporediti s onima dobivenim izokonverzijskim metodama. U slučaju da statistički najbolji model ima i najbolje slaganje s aktivacijskom energijom izračunatom izokonverzijskom metodom, tada se takav model može prihvatiti kao kinetički model istraživanog procesa. U ovom radu primijenjena je metoda F-testa, a testirani modeli prikazani su u tablici 1 .

Tablica 1 - Kinetički modeli i pripadajuće jednadžbe: de/dt $=-A \exp (E / R T) f(\mathrm{e}, p)$, gdje je $\mathrm{e}=(1-\alpha)$ i $p=\alpha$ kako ih koristi program Netzsch Thermokinetic ${ }^{16}$

Table 1 - Reaction model types and corresponding equations: de/dt $=-A \exp (E / R T) f(e, p)$, where $\mathrm{e}=(1-\alpha)$ and $p=\alpha$ as used by Netzsch Thermokinetic software ${ }^{16}$

\begin{tabular}{c|c|l}
\hline Oznaka & $f(e, p)$ & Mehanizam (kinetički modeli) \\
\hline F1 & $e$ & Reakcija prvog reda \\
\hline F2 & $e^{2}$ & Reakcija drugog reda \\
\hline Fn & $e^{n}$ & Reakcija $n$-tog reda \\
\hline R2 & $2 e^{1 / 2}$ & Reakcija na granici faza (cilindrična simetrija) \\
\hline R3 & $3 e^{2 / 3}$ & Reakcija na granici faza (sferična simetrija) \\
\hline D1 & $0,5 /(1-e)$ & Jednodimenzijska difuzija \\
\hline D2 & $-1 / \ln (e)$ & Dvodimenzijska difuzija \\
\hline D3 & $1,5 e^{1 / 3} /\left(e^{-1 / 3}-1\right)$ & Trodimenzijska difuzija (Jander) \\
\hline D4 & $1,5 /\left(e^{-1 / 3}-1\right)$ & Trodimenzijska difuzija (Ginstling-Brounstein) \\
\hline B1 & $e p$ & Prout-Tompkinsova jednadžba \\
\hline Bna & $e^{n} p^{a}$ & Proširena Prout-Tompkinsova jednadžba (na) \\
\hline C1-X & $e\left(1+K_{\text {cat }} X\right)$ & Reakcija prvog reda s autokatalizom, $X=p$ \\
\hline Cn-X & $e^{n}\left(1+K_{\text {cat }} X\right)$ & Reakcija n-tog reda s autokatalizom, $X=p$ \\
\hline A2 & $2 e(-\ln (e))^{1 / 2}$ & Dvodimenzijska statistička nukleacija i rast (Avrami-Erofeev) \\
\hline A3 & $3 e\left(-\ln (e)^{2 / 3}\right.$ & Trodimenzijska statistička nukleacija i rast (Avrami-Erofeev) \\
\hline An & $n e(-\ln (e))^{(n-1) / n}$ & $n$-dimenzijska statistička nukleacija i rast (Avrami-Erofeev) \\
\hline
\end{tabular}



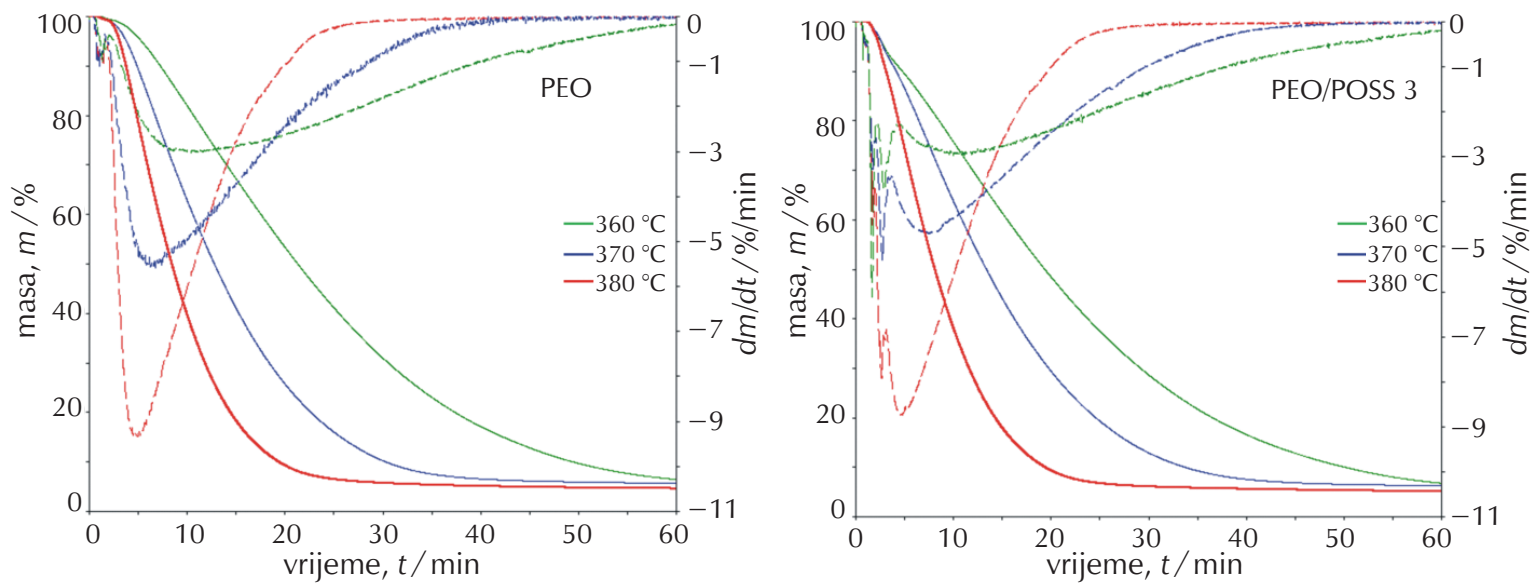

Slika 2 - TG i DTG krivulje izotermne razgradnje PEO-a i nanokompozita PEO/POSS 3

Fig. 2 - TG and DTG curves of isothermal degradation of PEO and PEO/POSS 3 nanocomposite
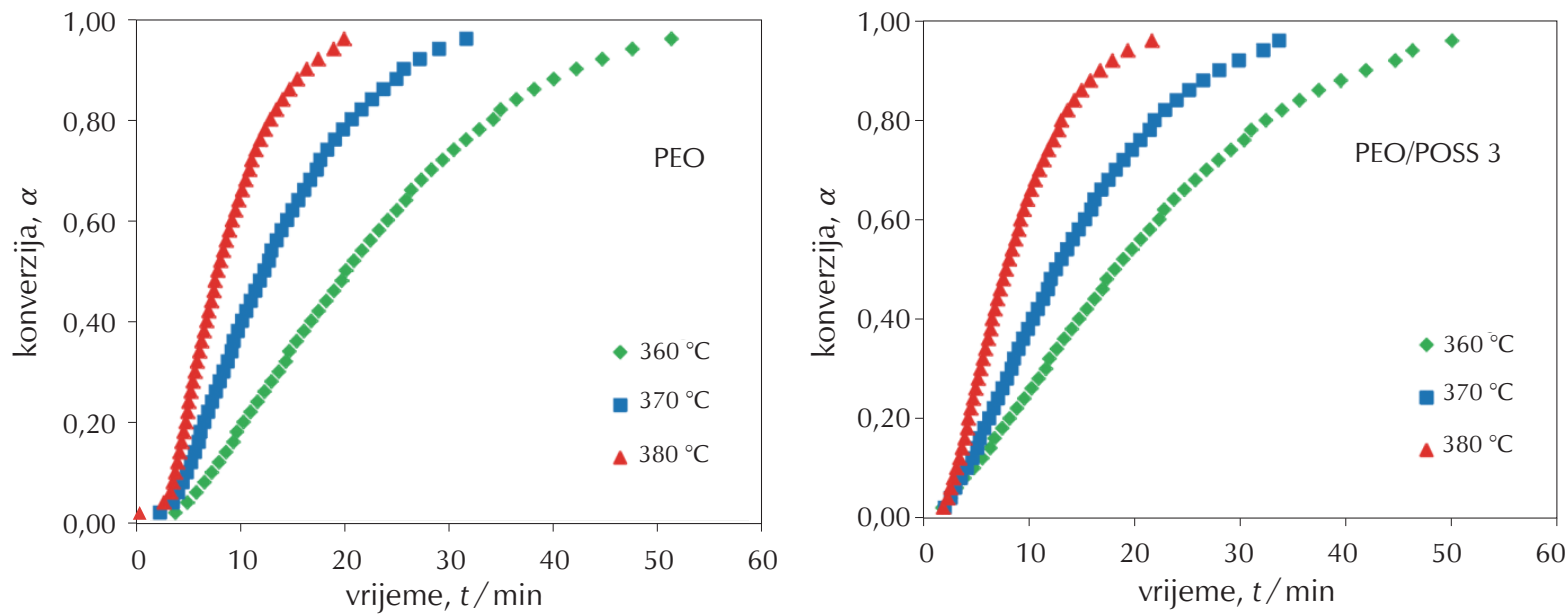

Slika 3 - Ovisnost konverzije o vremenu za PEO i nanokompozit PEO/POSS 3

Fig. 3 - Dependance of conversion on time for PEO and PEO/POSS 3 nanocomposite

\section{Rezultati i rasprava}

\subsection{Izotermna termogravimetrijska razgradnja}

Rezultat termogravimetrijske analize nanokompozita $\mathrm{PEO} /$ f,hib-POSS pri različitim temperaturama jesu TG krivulje koje predstavljaju gubitak mase uzorka u ovisnosti o vremenu. Na slici 2 prikazane su TG krivulje izotermne razgradnje čistog PEO-a i nanokompozita PEO/POSS 3. Iz TG krivulja očitana je ostatna masa nakon 60 min zagrijavanja pri odabranoj temperaturi. Prema podatcima prikazanima u tablici 2 može se zaključiti da pri temperaturama 360,370 i $380{ }^{\circ} \mathrm{C}$ svi uzorci nakon 60 min dostižu plato konstantne mase, uz ostatnu masu $\left(m_{\mathrm{f}}\right) 3-7 \%$ od početne mase uzorka.

Iz grafičkog prikaza ovisnosti konverzije $\alpha$ o vremenu $t$ vidljivo je da se povećanjem temperature vrijeme potrebno za dostizanje određene konverzije smanjuje (slika 3). Konverzija je definirana kao omjer $\alpha=\left(m_{\mathrm{o}}-m_{\mathrm{t}}\right) /\left(m_{\mathrm{o}}-m_{\mathrm{f}}\right)$, gdje je $m_{\mathrm{o}}$ - početna masa uzorka, $m_{\mathrm{t}}-$ masa u vremenu $t$ i $m_{\mathrm{f}}$ - masa nakon 60 min razgradnje.
Tablica 2 - Ostatna masa, $m_{\mathrm{f}}$, nakon 60 min izotermne razgradnje nanokompozita $\mathrm{PEO} / \mathrm{f}$,hib-POSS

Table 2 - Final mass, $m_{\mathrm{f}}$ after $60 \mathrm{~min}$ of isothermal degradation of PEO/f,hib-POSS nanocomposites

\begin{tabular}{c|c|c|c}
\hline \multirow{2}{*}{$\begin{array}{c}\text { Uzorak } \\
\text { Sample }\end{array}$} & \multicolumn{3}{|c}{$\begin{array}{c}\text { Ostatna masa, } m_{\mathrm{f}} / \% \\
\text { Final mass, } m_{\mathrm{f}} / \%\end{array}$} \\
\cline { 2 - 4 } & $360{ }^{\circ} \mathrm{C}$ & $370{ }^{\circ} \mathrm{C}$ & $380{ }^{\circ} \mathrm{C}$ \\
\hline PEO & 6,2 & 5,6 & 4,2 \\
\hline PEO/POSS 1 & 6,4 & 3,7 & 3,8 \\
\hline PEO/POSS 2 & 6,6 & 4,0 & 3,7 \\
\hline PEO/POSS 3 & 6,5 & 6,3 & 5,1 \\
\hline PEO/POSS 4 & 6,8 & 4,4 & 3,7 \\
\hline PEO/POSS 5 & 6,3 & 4,6 & 3,2 \\
\hline
\end{tabular}

Prema podatcima dostupnim u literaturi toplinska razgradnja PEO-a odvija se mehanizmom statističkog cijepanja lanca, pri čemu nastaju niskomolekulski spojevi, uglav- 
nom $\alpha$-peroksidi i esteri mravlje kiseline. ${ }^{15}$ Pri povišenoj temperaturi POSS najprije sublimira i na taj način gubi neznatan dio početne mase, a kasnije, pri višim temperaturama dolazi do konkretnijeg gubitka mase, odnosno do toplinske razgradnje POSS-a. Cisti prahovi f,hib-POSS-a i to fenil hib-POSS, 4-metil hib-POSS, 4-metoksi hib-POSS i 4-fluoro hib-POSS razgrađuju se $u$ inertnoj atmosferi $u$ temperaturnom području $200-400{ }^{\circ} \mathrm{C}$, pri čemu se razgradi približno $98 \%$ početne mase uzorka. ${ }^{13}$

\subsection{Kinetička analiza}

Kako je ranije opisano, sukladno preporukama ICTAC-a, kinetička analiza započinje određivanjem ovisnosti aktivacijske energije o konverziji. Kako bi se kinetička analiza mogla primijeniti samo za izotermne uvjete, pomoću programa Pyris određeno je vrijeme potrebno za zagrijavanje uzorka od početne temperature na temperaturu izotermne razgradnje $\left(360,370\right.$ i $\left.380{ }^{\circ} \mathrm{C}\right)$ te je kao nulto uzeto vrijeme kada su postignuti izotermni uvjeti. U tu svrhu u programu Pyris izračunate su DTG krivulje (slika 2), gdje je prvi pik posljedica zagrijavanja od početne do temperature izotermne razgradnje. Vrijeme završetka prvog pika uzeto je kao vrijeme početka izotermne razgradnje. Na slici 4 prikazane su tako korigirane izotermne TG krivulje PEO-a i nanokompozita PEO/POSS 3.
Pomoću programa Netzsch Thermokinetics Professional izračunata je aktivacijska energija diferencijalnom izokoverzijskom metodom koja se temelji na jedn. (4). Ovisnost aktivacijske energije $(E)$ o konverziji prikazana je na slici 5 za sve istraživane uzorke. Vidljivo je da dodatak nanopunila utječe na aktivacijsku energiju razgradnje $\mathrm{PEO}-\mathrm{a}$, a također i vrsta supstituenta na fenilnoj skupini POSS-a.

Najvišu vrijednost $E$ ima uzorak koji sadrži POSS 4 (4-fluoro fenil hib-POSS), dok najnižu vrijednost $E$ ima uzorak PEO/POSS 2 (sadrži 4-metil fenil hib-POSS). Naime, utvrđeno je da POSS 2 ima najnižu temperaturu početka razgradnje i najnižu temperaturu pri najvećoj brzini neizotermne toplinske razgradnje, a POSS 4 najviše vrijednosti u odnosu na istraživane uzorke POSS-a, ${ }^{13}$ pa se te promjene aktivacijske energije mogu izravno povezati s toplinskom postojanošću POSS punila. Aktivacijska energija toplinske razgradnje nanokompozita PEO/POSS 1, PEO/POSS 3 i PEO/POSS 5 znatno se ne mijenja u odnosu na PEO. Ovisnost aktivacijske energije o konverziji pokazuje sličan oblik kod svih uzoraka, pa se može zaključiti da je sličan i mehanizam toplinske razgradnje. DTG krivulje svih analiziranih uzoraka (na slici 2 prikazani su primjeri PEO-a i uzoraka PEO/POSS 3) prikazuju samo jedan pik u području izotermne razgradnje, što ukazuje na jednostupanjski proces izotermne razgradnje. Nadalje, slika 5 pokazuje da u vrlo širokom području konverzija, vrijedno-
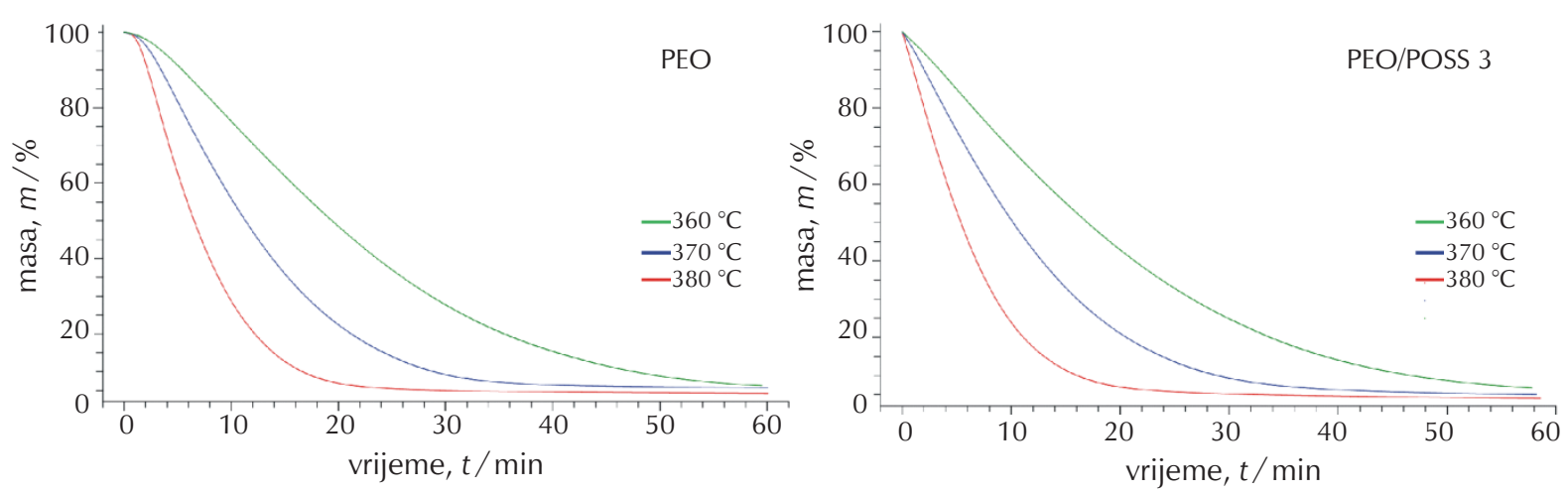

Slika 4 - Korigirane izotermne TG krivulje PEO-a i nanokompozita PEO/POSS 3 Fig. 4 - Corrected isothermal TG curves of PEO and PEO/POSS 3 nanocomposite

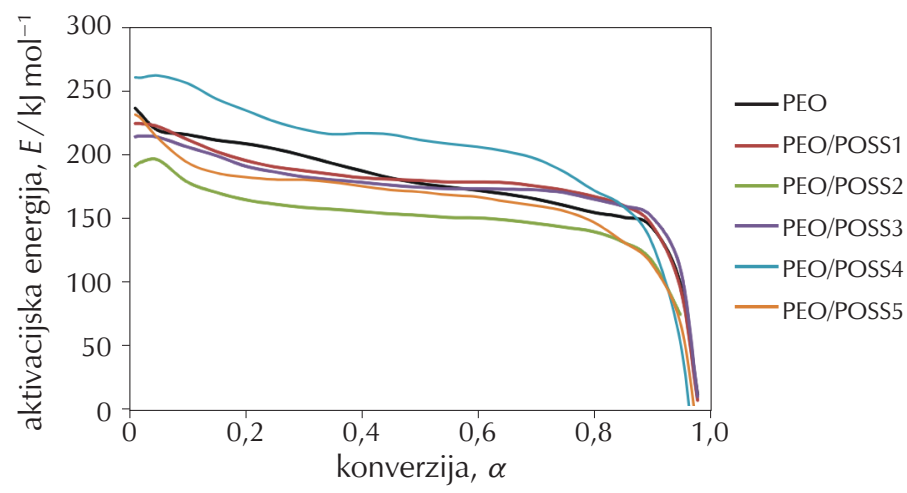

Slika 5 - Ovisnost aktivacijske energije o konverziji

Fig. 5 - Dependance of activation energy on conversion 
sti aktivacijske energije odstupaju od srednje vrijednosti u granicama koje preporuke ICTAC ${ }^{14}$ smatraju dopuštenim za jednostupanjske procese. To znači da je razlika između izračunate maksimalne i minimalne vrijednosti manja od $30 \%$ u odnosu na srednju vrijednost aktivacijske energije te se taj proces $s$ kinetičke točke gledišta može smatrati jednostavnim jednostupanjskim procesom. Stoga je u kinetičkoj analizi primijenjena linearna regresija (LR) kojom su određeni kinetički modeli koji najbolje opisuju proces izotermne razgradnje PEO-a i uzoraka PEO/POSS. Kao kriterij za određivanje koji od testiranih kinetičkih modela statistički najbolje opisuje ili opisuju proces neizotermne toplinske razgradnje PEO-a primijenjen je tzv. F-test. Prema F-testu, slaganje eksperimentalnih podataka s kinetičkim modelom računa se prema jedn. (7):

$$
S_{j}^{2}=\frac{1}{n-1} \sum_{i=1}^{n}\left((\mathrm{~d} \alpha / \mathrm{d} t)_{\exp }-(\mathrm{d} \alpha / \mathrm{d} t)_{\text {model }}\right)^{2},
$$

gdje je $S^{2}$ j varijanca, $n$ broj mjernih točaka, $(\mathrm{d} \alpha / \mathrm{d} t)_{\exp }$ eksperimentalne, a $(\mathrm{d} \alpha / \mathrm{d} t)_{\text {model }}$ izračunate vrijednosti za pojedini kinetički model. Ukoliko se vrijednosti varijance pojedinog modela $S^{2}$ podijele s minimalnom vrijednosti varijance $S^{2}{ }_{\text {min }}$ svih promatranih modela, provodi se tzv. F-test i dobiju se vrijednost $F_{\text {exp }}(8)$ :

$$
F_{\text {exp }}=\frac{S_{j}^{2}}{S_{\min }^{2}}<F_{\text {krit. }}
$$

Prema F-testu, samo oni modeli koji zadovoljavaju jedn. (8), tj. za koje vrijedi $F_{\text {exp }}<F_{\text {krit }}$ smatraju se statistički vjerojatnim modelima za opis promatranog procesa. Pri tome je $F_{\text {krit }}$ vrijednost koja se izračunava na temelju broja eksperimentalnih točaka (ovdje 4065 eksperimentalnih točaka) i razini statističke značajnosti (ovdje 0,05 ), odnosno statističke vjerojatnosti $(1-0,05=0,95) . F_{\text {krit }}$ za sve uzorke i modele izračunata programom Netzsch Thermokinetics za navedeni broj točaka i statističku vjerojatnost iznosi $F_{\text {krit }}=1,03$. Rezultati statističkog $F$-testa prikazani u tablici 3.

Rezultati pokazuju da tzv. prošireni Prout-Tompkinsov kinetički model Bna najbolje opisuje proces izotermne toplinske razgradnje PEO-a, dok su Avrami-Erofeev kinetički model (An), model prvog reda s autokatalizom (C1B) i $n$-tog reda s autokatalizom (CnB) također statistički vjerojatni modeli za opis procesa izotermne toplinske razgradnje PEO-a budući da za njih vrijedi $F_{\text {exp }}<F_{\text {krit }}$. Pri tome su C1B i CnB jednaki modeli budući da je u modelu CnB izračunata vrijednost $n=1,00$. Dobiveni rezultati su $u$ skladu s onima u literaturi, ${ }^{17}$ gdje je također nađeno da Bna i An kinetički modeli statistički najbolje opisuju proces neizotermne toplinske razgradnje PEO-a. Iz toga se može izvesti zaključak da promjena uvjeta razgradnje ne utječe na mehanizam toplinske razgradnje PEO-a, koji se odvija statističkim cijepanjem makromolekulnih lanaca PEO-a bez depolimerizacije. ${ }^{18}$ Rezultat je očekivan budući da svi ti ispitivani modeli (Bna, An, C1B i CnB) opisuju autokatalitičke reakcije kakva je toplinska razgradnja

Table 3 - Rezultati F-testa za sve kinetičke modele testirane pomoću programa Netzsch Thermokinetics Professional

\begin{tabular}{|c|c|c|c|c|c|c|c|c|c|c|c|}
\hline \multicolumn{2}{|c|}{ PEO } & \multicolumn{2}{|c|}{ PEO/POSS 1} & \multicolumn{2}{|c|}{ PEO/POSS 2} & \multicolumn{2}{|c|}{ PEO/POSS 3} & \multicolumn{2}{|c|}{ PEO/POSS 4} & \multicolumn{2}{|c|}{ PEO/POSS 5} \\
\hline$F_{\text {exp }}$ & MODEL & $F_{\text {exp }}$ & MODEL & $F_{\text {exp }}$ & MODEL & $F_{\text {exp }}$ & MODEL & $F_{\text {exp }}$ & MODEL & $F_{\text {exp }}$ & MODEL \\
\hline 1,00 & Bna & 1,00 & $\mathrm{Cn} \mathrm{B}$ & 1,00 & Cn B & 1,00 & $\mathrm{Cn} B$ & 1,00 & $\mathrm{Cn} B$ & 1,00 & $\mathrm{Cn} B$ \\
\hline 1,01 & An & 1,00 & $\mathrm{C} 1 \mathrm{~B}$ & 1,00 & C1B & 1,00 & $\mathrm{Bn} A$ & 1,00 & $\mathrm{C} 1 \mathrm{~B}$ & 1,05 & $\mathrm{C} 1 \mathrm{~B}$ \\
\hline 1,03 & $\mathrm{C} 1 \mathrm{~B}$ & 1,01 & $\mathrm{BnA}$ & 1,00 & $\mathrm{BnA}$ & 1,03 & C1 B & 1,12 & $\mathrm{BnA}$ & 1,07 & $\mathrm{BnA}$ \\
\hline 1,03 & $\mathrm{CnB}$ & 1,05 & An & 3,00 & An & 1,11 & An & 1,19 & An & 1,29 & An \\
\hline 1,50 & Fn & 1,19 & $\mathrm{Fn}$ & 1,08 & Fn & 1,26 & Fn & 1,64 & Fn & 1,49 & $\mathrm{Fn}$ \\
\hline 1,50 & R2 & 1,23 & R3 & 1,39 & R3 & 1,36 & R3 & 1,75 & R3 & 1,59 & R3 \\
\hline 1,97 & R3 & 1,38 & $\mathrm{R} 2$ & 2,19 & $\mathrm{R} 2$ & 1,58 & $\mathrm{R} 2$ & 2,30 & $\mathrm{R} 2$ & 2,46 & $\mathrm{R} 2$ \\
\hline 5,07 & $\mathrm{~A} 2$ & 3,48 & $\mathrm{~F} 1$ & 5,63 & $\mathrm{~F} 1$ & 5,58 & $\mathrm{~F} 1$ & 8,17 & $\mathrm{~F} 1$ & 9,66 & $\mathrm{~F} 1$ \\
\hline 5,32 & $\mathrm{~F} 1$ & 6,81 & D1 & 12,97 & D1 & 11,38 & D1 & 19,18 & D1 & 21,76 & D1 \\
\hline 9,82 & D1 & 7,18 & $\mathrm{~A} 2$ & 116,36 & $\mathrm{~A} 2$ & 12,38 & $\mathrm{~A} 2$ & 21,35 & $\mathrm{~A} 2$ & 27,25 & $\mathrm{~A} 2$ \\
\hline 14,60 & D1F & 10,85 & D1F & 21,34 & D1F & 18,99 & D1F & 30,93 & D1F & 37,13 & D1F \\
\hline 15,45 & $\mathrm{~A} 3$ & 12,01 & D2 & 23,67 & $\mathrm{D} 2$ & 20,97 & D2 & 35,28 & D2 & 41,41 & D2 \\
\hline 13,26 & D2 & 15,02 & D4 & 30,28 & D4 & 26,52 & D4 & 44,39 & D4 & 52,96 & D4 \\
\hline 19,57 & D4 & 18,62 & A3 & 39,13 & D3F & 33,46 & D3F & 55,96 & D3F & 68,06 & D3F \\
\hline 23,63 & D3f & 18,94 & D3F & 42,62 & A3 & 33,71 & A3 & 58,10 & A3 & 73,43 & A3 \\
\hline 26,75 & D3f & 21,87 & D3 & 45,68 & D3 & 39,04 & D3 & 65,06 & D3 & 79,39 & D3 \\
\hline 27,60 & $\mathrm{~F} 2$ & 24,29 & $\mathrm{~F} 2$ & 52,30 & $\mathrm{~F} 2$ & 42,77 & $\mathrm{~F} 2$ & 70,92 & $\mathrm{~F} 2$ & 88,46 & F2 \\
\hline 42,02 & B1 & 45,44 & B1 & 102,77 & B1 & 82,76 & B1 & 144,41 & B1 & 180,34 & B1 \\
\hline
\end{tabular}

Tablica 3 - Results of F-test for all kinetic models tested by Netzsch Thermokinetics Professional software

$F_{\text {krit }}(0,95)=1,03$ za sve uzorke i modele 
Table 4 - Rezultati linearne regresijske analize

Tablica 4 - Results of linear regression analysis

\begin{tabular}{c|c|c|c|c|c|c}
\hline & PEO & PEO/POSS 1 & PEO/POSS 2 & PEO/POSS 3 & PEO/POSS 4 & PEO/POSS 5 \\
\hline$E / \mathrm{kJ} \mathrm{mol}^{-1}$ & 179,8 & 173,8 & 149,9 & 172,9 & 215,1 & 168,9 \\
\hline $\log A / \mathrm{s}^{-1}$ & 11,8 & 11,12 & 9,18 & 11,06 & 14,52 & 10,73 \\
\hline \multirow{2}{*}{$f(\alpha)$} & Bna & CnB & CnB & CnB & CnB & CnB \\
& $n=0,83$ & $n=0,95$ & $n=0,98$ & $n=0,91$ & $n=0,99 \quad n=0,92$ \\
\hline
\end{tabular}
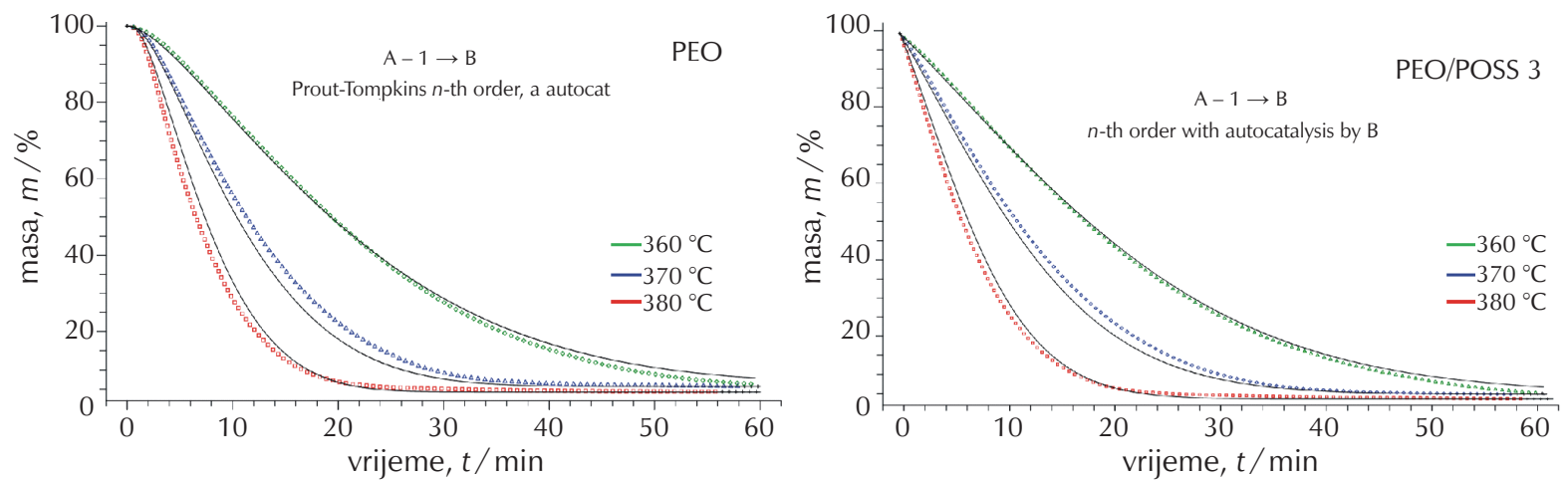

Slika 6 - Usporedba izračunatih i eksperimentalnih TG krivulja za PEO i PEO/POSS 3

Fig. 6 - Comparison of calculated and experimental curves of PEO and PEO/POSS 3

PEO-a. Na takav zaključak upućuju i $\alpha-t$ podatci (slika 3) budući da je sigmoidalni oblik tih krivulja karakterističan za autokatalitičke procese. Svi modeli pokazuju praktično iste vrijednosti aktivacijskih energija $\left(180,0 \pm 0,2 \mathrm{kJmol}^{-1}\right)$. Kinetički model $\mathrm{CnB}$ najbolje opisuje razgradnju svih PEO/POSS uzoraka, dok su kod PEO/POSS 1, PEO/POSS 2 i PEO/POSS 3 statistički jednako vjerojatni Bna i C1B kinetički modeli. Kod uzorka PEO/POSS $4 n=0,99$ pa su modeli CnB i C1B jednaki, sukladno objašnjenju danom kod opisa procesa izotermne toplinske razgradnje PEO-a.

Kinetički modeli $f(\alpha)$ koji najbolje opisuje razgradnju promatranih uzoraka i pripadajuće vrijednosti aktivacijske energije $(E)$ i predeksponencijalnog faktora $(A)$ izračunati primjenom linearne regresijske analize (LR) prikazani su u tablici 4. Vrijednosti $E$, A i $f(\alpha)$ izračunate su za područje konverzija $\alpha=0,04-0,90$.

Na slici 6 uočeno je vrlo dobro slaganje eksperimentalnih i izračunatih TG krivulja za PEO i PEO/POSS 3, a dobro slaganje nađeno je i za ostale uzorke PEO/POSS.

\section{Zaključak}

Na temelju TG i DTG krivulja i rezultata kinetičke analize utvrđeno je da je izotermna toplinska razgradnja PEO-a i nanokompozita PEO/POSS jednostupanjski proces koji najbolje opisuju autokatalitički modeli. Aktivacijska energija toplinske razgradnje nanokompozita PEO/POSS 1, PEO/POSS 3 i PEO/POSS 5 znatno se ne mijenja u odnosu na PEO. Niža vrijednost aktivacijske energije uzorka PEO/POSS 2 i viša vrijednost aktivacijske energije uzorka
PEO/POSS 4 u odnosu na PEO može se pripisati slabijoj odnosno boljoj toplinskoj postojanosti samih nanopunila.

\section{Literatura \\ References}

1. E. Quartatone, P. Mustareli, P. Magistris, PEO-based composite polymer electrolytes, Solid State Ion. 110 (1998) 1-14, doi: https://doi.org/10.1016/S0167-2738(98)00114-3.

2. H.-W. Chen, F.-C. Chang, The novel polymer electrolyte nanocomposite composed of poly(ethylene oxide), lithium triflate and mineral clay, Polymer 42 (2001) 9763-9769, doi: https://doi.org/10.1016/S0032-3861(01)00520-1.

3. G. Sandi, K. A. Carrado, H. Joachin, W. Lu, J. Praksh, Polymer nanocomposites for lithium battery applications, J. Power Sources 119 (2003) 492-496, doi: https://doi.org/10.1016/ S0378-7753(03)00272-6.

4. C.-S. Lio, W.-B. Ye, Enhanced lonic Conductivity in Poly(ethylene oxide)/Layered Double Hydroxide Nanocomposite Electrolytes, J. Polym. Res. 10 (2003) 241-246, doi: https:// doi.org/10.1023/B:JPOL.0000004619.00197.7a.

5. C. H. Manoratne, R. M. G. Rajapakse, M. A. K. L. Dissanayake, Ionic conductivity of poly (ethylene oxide)(PEO)-montmorillonite (MMT) nanocomposites prepared by intercalation from aqueous medium, Int. J. Electrochem. Sci. 1 (2006) 32-46.

6. G. Ilia, E. Fagadar-Cosma, S. liescu, L. Macarie, N. Pleşu, G. Fagadar-Cosma, A. Popa, Solid Polymer Electrolytes for Batteries, Editura Mirton, Timisoara, 2013.

7. X. Zhignag, D. He, X. Xie, Poly(ethylene oxide)-based electrolytes for lithium-ion batteries, J. Mater. Chem. A 3 (2015) 19218-19253, doi: https://doi.org/10.1039/C5TA03471J.

8. M. M. E. Jacob, E. Hackett, E. P. Giannelis, Synthesis and 
characterization of Ag/PVA nanocomposite by chemical reduction method, J. Mater. Chem. 13 (2003) 1-5, doi: https:// doi.org/10.1016/j.matchemphys.2005.02.029.

9. R. C. Agrawal, G. P. Pandey, Solid polymer electrolytes: materials designing and all-solid-state battery applications: an overview, J. Phys. D. Appl. Phys. 41 (2008) 1-18, doi: https://doi.org/10.1088/issn.0022-3727.

10. M. Erceg, D. Jozić, I. Banovac, S. Perinović, S. Bernstorff, Preparation and characterization of melt intercalated poly(ethylene oxide)/lithium montmorillonite nanocomposites, Thermochim. Acta 579 (2014) 86-92, doi: https://doi. org/10.1016/j.tca.2014.01.024.

11. M. Erceg, I. Krešić, M. Jakić, B. Andričić, Kinetic analysis of poly(ethylene oxide)/lithium montmorillonite nanocomposites, J. Therm. Anal. Calorim. 127 (2017) 789-797, doi: https://doi.org/10.1007/s10973-016-5413-y.

12. I. Blanco, The Rediscovery of POSS: A Molecule Rather than a Filler, Polymers 10 (2018) 904-1004, doi: https://doi. org/10.3390/polym10080904.

13. I. Blanco, L. Abate, F. A. Bottino, P. Bottino, Hepta isobutyl polyhedral oligomeric silsesquioxanes (hib-POSS): A ther- mal degradation study. J. Therm. Anal. Calorim. 108 (2012) 807-815, doi: https://doi.org/10.1007/s10973-011-2050-3.

14. S. Vyazovkin, A. K. Burnham, J. M. Criado, L. A. Pérez-Maqueda, C. Popescu, N. Sbirrazzuoli, ICTAC Kinetics Committee recommendations for performing kinetic computations on thermal analysis data, Thermochim. Acta 520 (2011) 1-19, doi: https://doi.org/10.1016/j.tca.2011.03.034.

15. K. Pielichowski, K. Flejtuch, Non-oxidative thermal degradation of poly (ethylene oxide): kinetic and thermoanalytical study, J. Anal. Appl. Pyrolysis 73 (2005)131-138, doi: https://doi.org/10.1016/j.jaap.2005.01.003.

16. Netzsch Thermokinetics Software Manual, Selb: Netzsch Gerätebau GmbH; 2014.

17. M. Erceg, I. Krešić, N. Stipanelov Vrandečić, M. Jakić, Different approaches to the kinetic analysis of thermal degradation of poly (ethylene oxide), J. Therm. Anal. Calorim. 131 (2018) 325-334, doi: https://doi.org/10.1007/s10973-017-6349-6.

18. S. L. Madorsky, S. Strauss, Thermal degradation of polyethylene oxide and polypropylene oxide. J. Polym. Sci. 36 (1959) 183-194, doi: https://doi.org/10.1002/ pol.1959.1203613015.

\title{
EXTENDED ABSTRACT
}

\author{
Kinetic Analysis of Isothermal Degradation of \\ Polylethylene oxide) Modified by Phenyl Hepta Isobutyl Polyhedral \\ Oligomeric Silsesquioxanes \\ Nataša Stipanelov Vrandečić, Matko Erceg, Branka Andričić, and Petra Ćerdić
}

Poly(ethylene oxide) (PEO) and lithium salts based solid polymer electrolytes exhibit low ionic conductivity at the service temperatures, the main reason being the high crystallinity of PEO. Degree of crystallinity is often lowered by addition of nanoparticles, among them being a very interesting group known as polyhedral oligomeric silsesquioxanes (POSSs). In this work, the influence of POSS nanoparticles (methyl-, fluoro-, and chloro-phenil heptaisobutyl POSS) on kinetics of isothermal PEO degradation was investigated. Activation energy, pre-exponential factor, and kinetic model were determined using Netzsch Thermokinetics Professional program. It was found that the process of isothermal degradation occurs through one step, best described by autocatalytic models. According to Fig. 2 and Table 2, all investigated samples at 360,370 , and $380{ }^{\circ} \mathrm{C}$ after 60 min reach constant mass plateau with residual mass $\left(m_{\mathrm{f}}\right) 3-7 \%$. In this temperature range, degradation of both PEO and POSSs occur. Before starting the kinetic analysis, the time necessary to gain isothermal conditions was subtracted. Activation energy $(E)$ and pre-exponential factor $(A)$ calculated using linear regression (LR), as well as the kinetic model of thermal degradation $f(\alpha)$ are summarised in Table 4. Activation energies of PEO/POSS 1, PEO/POSS 3 i PEO/POSS 5 samples are similar to those of PEO. The highest and lowest value of activation energy for PEO/POSS 4 and PEO/POSS 2 samples, respectively, is the result of their inherent thermal stability. Dependence of activation energy on conversion is of the same shape for all samples, implying the same mechanism of thermal degradation. DTG curves exhibit one degradation step only. Results of F-test (Table 3) indicate that extended Prout-Tompkins model as well as other autocatalytic models are statistically the best for description of the isothermal degradation of PEO and PEO/POSS composites. Also, the sigmoidal shape of degradation curves (Fig. 3) is characteristic for autocatalytic processes. Finally, calculated models are in very good agreement with experimental data (Fig. 6).

\section{Keywords}

Isothermal degradation, kinetic analysis, polyhedral oligomeric silsesquioxanes, poly(ethylene oxide)

Faculty of Chemistry and Technology

Ruđera Boškovića 35

21000 Split, Croatia

Original scientific paper Received December 4, 2019 Accepted February 26, 2020 